\title{
Preventive effect of sensorimotor exercise and resistance training on chemotherapy-induced peripheral neuropathy: a randomised-controlled trial
}

\author{
Jana Müller $\mathbb{D}^{1,2,3}$, Markus Weiler $\mathbb{D}^{4}$, Andreas Schneeweiss $\mathbb{D}^{2,5}$, Georg Martin Haag $\mathbb{D}^{6}$, Karen Steindorf (iD ${ }^{7}$, Wolfgang Wick (iD ${ }^{2,4}$ and \\ Joachim Wiskemann (iD) ${ }^{\text {凶}}$
}

(c) The Author(s) 2021

BACKGROUND: Chemotherapy-induced peripheral neuropathy (CIPN) is a common, unpleasant and usually long-lasting side effect of neurotoxic chemotherapeutic agents. This study aimed to investigate the preventive potential of sensorimotor- (SMT) and resistance training $(\mathrm{RT})$ on CIPN.

METHODS: Patients $(N=170)$ were randomised to SMT, RT or usual care (UC). Both exercise groups trained $3 \times /$ week for a total of $105 \mathrm{~min} /$ week during neurotoxic chemotherapy (mean length: 20 weeks). Before and 3 weeks after neurotoxic chemotherapy, CIPN signs/symptoms were assessed via Total Neuropathy Score (TNSr; primary endpoint) and EORTC QLQ-CIPN15 questionnaire. In addition, balance (centre of pressure), muscle strength (isokinetic), quality of life (QoL, EORTC QLQ-C30) and relative chemotherapy dose intensity (RDI) were investigated. The follow-up period covered 6 months after the end of chemotherapy.

RESULTS: Intention-to-treat analyses $(N=159)$ revealed no differences regarding CIPN signs/symptoms. Exploratory per-protocol analyses (minimum training attendance rate $67 \% ; N=89$ ) indicated that subjectively perceived sensory symptoms in the feet increased less during chemotherapy in the adherent exercisers (pooled group: SMT+RT) than in the UC group ( -8.3 points $(-16.1$ to -0.4$) ; P=0.039, E S=1.27)$. Furthermore, adherent exercisers received a higher RDI $(96.6 \pm 4.8$ vs. $92.2 \pm 9.4 ; P=0.045)$, showed a better course of muscular strength $(+20.8 \mathrm{Nm}(11.2-30.4) ; P<0.001, \mathrm{ES}=0.57)$ and $\mathrm{QoL}(+12.9$ points $(3.9-21.8) ; P=0.005, \mathrm{ES}=$ 0.64). During follow-up, CIPN signs/symptoms persisted in all groups.

CONCLUSIONS: This study demonstrates that SMT and/or RT alleviate subjectively perceived sensory CIPN symptoms in the feet and other clinically relevant cancer therapy-related outcomes, if an appropriate training stimulus is achieved.

CLINICAL TRIAL REGISTRATION: NCT02871284.

British Journal of Cancer (2021) 125:955-965; https://doi.org/10.1038/s41416-021-01471-1

\section{INTRODUCTION}

Tingling, burning, numbness and pain in hands and/or feet may be observed from the first administration of neurotoxic drugs such as taxanes, platinum compounds or vinca alkaloids [1, 2]. The severity and persistence of chemotherapy-induced peripheral neuropathy (CIPN) are mainly dependent on drug type and cumulative dose, but probably also on comorbidities and lifestyle factors such as obesity and low moderate-to-vigorous physical activity [3, 4]. The primary sensory symptoms and resulting functional limitations, such as balance and gait difficulties, may persist over several years/decades in up to $50 \%$ of patients [5-8], causing reduced individual independence and quality of life [6], but also probably increased cancer recurrence and mortality rates, due to chemotherapy dose reductions and early treatment termination [9].

The reduction of chemotherapy dose is currently the only way to prevent the progression of CIPN symptoms. However, the body of research is constantly growing investigating the effects of various prevention and rehabilitation measures, such as exercise therapy. After chemotherapy, exercise is shown to positively affect various aspects of CIPN [10-15]. However, the preventive potential has been so far less investigated and the results are sometimes divergent. Positive intervention effects were found for deep sensitivity [16], perception of hot and coldness [17] and static balance performance [18]. All other studies were not able to detect a positive influence on CIPN signs/symptoms or functional

\footnotetext{
${ }^{1}$ Working Group Exercise Oncology, Division of Medical Oncology, National Center for Tumor Diseases (NCT) and Heidelberg University Hospital, Heidelberg, Germany.

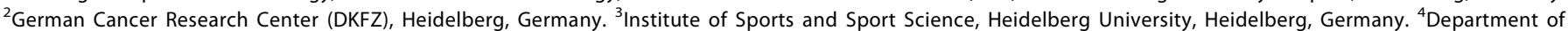

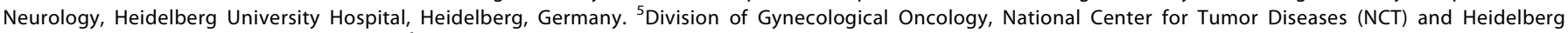

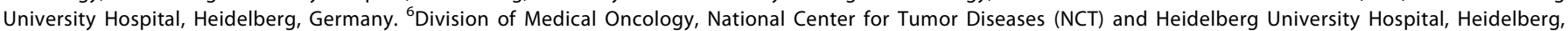

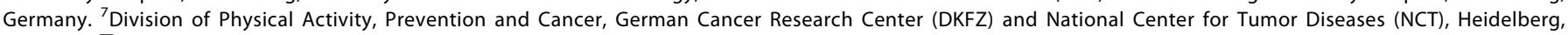
Germany. ${ }^{凶}$ email: joachim.wiskemann@nct-heidelberg.de
} 
limitations [19-21], which might be due to the following methodological issues: small sample sizes $(N=19-43)[16,18-21]$, blurred baseline values by performing baseline measurement after the first chemotherapy administration [16, 21], and rudimentary CIPN assessment. Regarding CIPN assessment, it is recommended in the current literature to combine both subjective and objective CIPN diagnostics [22]. However, only one study complies with the current literature recommendations [19]. All other studies used either singular subjective assessments (ranging from simple, nonpsychometrically tested symptom queries to the use of recommended questionnaires $[17,18,20,21])$, or a singular objective test (tuning fork [16]). On this basis, we conducted a single-centre randomised-controlled three-arm intervention trial. The primary aim of the PIC study was to evaluate the preventive potential of sensorimotor exercise training (SMT) and resistance training (RT) versus usual care (UC) during neurotoxic chemotherapy on clinically objectified CIPN signs/symptoms by means of the Total Neuropathy Score (TNSr). The SMT represented a specific training approach guided by the CIPN symptoms (especially the balance impairment), while the RT was tested as a non-specific training approach. We hypothesised that patients randomised to the SMT or RT group would have a smaller change on the TNSr score over the course of neurotoxic chemotherapy in comparison to patients receiving UC.

\section{METHODS}

\section{Study design and participants}

The PIC study was a single-centre randomised-controlled three-arm exercise intervention trial. Ethical approval was obtained (Ethics Committee Medical Faculty University of Heidelberg: S-630/2015) and the trial was registered before activation (ClinicalTrials.gov: NCT02871284). Patients were eligible if they were $\geq 18$ years of age and were admitted to receive neurotoxic chemotherapy, which had not been started at the time of study assignment and baseline testing (see Table 1 for complete inclusion/ exclusion criteria).

\section{Procedures}

Potentially eligible patients were identified by their physicians or through hospital records at the National Center for Tumor Diseases (NCT, Heidelberg, Germany) or regional cooperation clinics between March 2016 and June 2018. After providing written informed consent and completed baseline testing (pre), patients were randomly assigned to an exercise intervention (SMT or RT) or UC group. The allocation was done by an independent person (i.e. not involved in patient recruitment) based on allocation lists generated by a computerised random number generator. These lists were generated prior to the inclusion of the first patient and were based on blocked randomisation with random block sizes of three and six, stratified by gender and type of treatment (taxanes, platinum derivatives, vinca alkaloids, combined neurotoxic chemotherapy). The personnel involved in the recruitment and baseline assessments were not involved in this process and had no access to these lists throughout the whole study. Three weeks after completion of the individual chemotherapy regime post $_{0}$ assessment took place. Follow-up assessments were

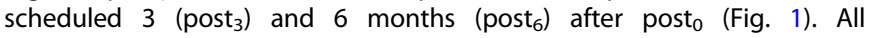
assessments were carried out in accordance with The Code of Ethics of the World Medical Association (Declaration of Helsinki, 2013).

\section{Outcomes}

CIPN signs and symptoms. The primary endpoint was the Total Neuropathy Score in its reduced version (TNSr) [23]. The TNSr represents a sum score of patient-reported symptoms (sensory, motor, autonomic) and clinical examinations of CIPN signs/symptoms (pinprick, reflexes, deep sensitivity, strength) as well as nerve conduction studies (NCS; motor: compound muscle action potential amplitude of peroneal nerve (CMAP), sensory: sensory nerve action potential amplitude of sural nerve (SNAP)), with higher values reflecting a greater symptom burden. In addition, the TNSc (TNSr without NCS), TNSm (without NCS and autonomic symptoms [24]) and the result variables of the NCS are reported separately: CMAP, SNAP, and nerve conduction velocities (NCV). To ensure data quality, all TNS assessments were blinded and performed according to general standards [23]. In addition, 94\% of the NCS (534 of 568 measurements) were carried out by the same technician with longstanding experience in clinical neurophysiology and peripheral neuropathy.

Furthermore, CIPN symptoms were assessed based on patients' perception by using the CIPN questionnaire of the European Organization for Research and Treatment of Cancer (EORTC QLQ-CIPN15) [25]. In contrast to the initially published scoring manual, the mean sum score was calculated over 15 instead of 20 items (hereinafter referred to as CIPN-15), with higher values expressing higher CIPN symptoms (score range 0-100) [26]. Since our main exercise intervention (SMT) particularly focused on the lower extremities, we exploratory defined two separate scores for sensory (items 2, 4, 6, 9) and motor symptoms (items 8, 14, 15) in the feet, in accordance to the lower extremity score [27].

Functional assessments. Postural control was assessed with a force plate (AMTI, AccuSway optimised, Watertown, USA). The detailed testing procedure is described elsewhere [28]. Briefly, patients were asked to stand as still as possible in bipedal stance with eyes closed $\left(\mathrm{BP}_{\mathrm{EC}}\right)$ for $30 \mathrm{~s}$. The best trial out of two was reported (lowest centre of pressure (COP) value for total mean velocity). In addition, we determined the average time of two trials patients were able to stand on one leg with open eyes (MPEO). Maximal voluntary isometric contraction for quadriceps was measured with an isokinetic dynamometer (IsoMed 2000-system B-series version, D\&R Ferstl $\mathrm{GmbH}$, Hemau, Germany). The test setup included a maximum force generation against the dynamometer arm for $6 \mathrm{~s}$ at a knee angle of $36^{\circ}$. Maximal peak torque was measured in the dominant leg, which was defined based on the higher peak torque of the right and left leg at baseline.

Table 1. Study inclusion and exclusion criteria.

\begin{tabular}{|c|c|}
\hline \multirow[t]{3}{*}{ Inclusion criteria } & - Age $\geq 18$ years \\
\hline & $\begin{array}{l}\text { - Diagnosed with cancer and assigned to receive a chemotherapeutic regimen containing at least one of the following agents: } \\
\text { - a platinum analogue, e.g. cisplatin, carboplatin, oxaliplatin } \\
\text { - a vinca alkaloid, e.g. vincristine } \\
\text { - a taxane, e.g. paclitaxel, docetaxel } \\
\text { - suramin } \\
\text { - thalidomide or lenalidomide } \\
\text { - bortezomib }\end{array}$ \\
\hline & - Physical capability to follow the training programme implemented within the exercise intervention groups \\
\hline \multirow{4}{*}{ Exclusion criteria } & - Positive family history for any hereditary peripheral neuropathy \\
\hline & - Known metastasis to the central or peripheral nervous system \\
\hline & $\begin{array}{l}\text { - Any physical or mental handicap that would hamper the performance of the training programme implemented within the } \\
\text { exercise intervention groups }\end{array}$ \\
\hline & $\begin{array}{l}\text { - Known history of alcohol or illegal drug abuse or any constellation of lab values suggesting alcoholism, e.g. elevated GGT, } \\
\text { MCV, CDT }\end{array}$ \\
\hline
\end{tabular}




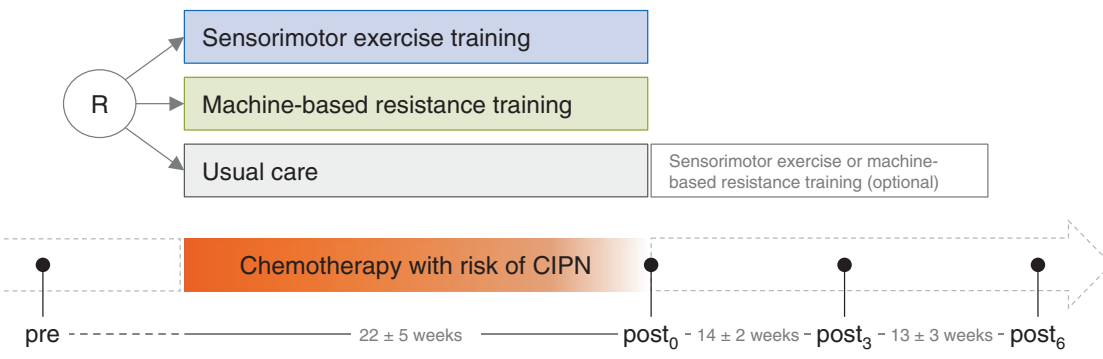

Fig. 1 Study design. CIPN chemotherapy-induced peripheral neuropathy, pre assessment point before neurotoxic chemotherapy, post $t_{0}$ assessment point 3 weeks after neurotoxic chemotherapy, post ${ }_{3}$ assessment point 3 months after post ${ }_{0}$, post ${ }_{6}$ assessment point 6 months after post $_{0}, R$ randomisation.

Patient-reported outcomes. Quality of life (QoL) was assessed with the validated EORTC QLQ-C30 questionnaire (version 3.0) [29, 30]. Fear of falling was assessed via Fall Efficacy Scale (FES-I) [31]. In addition, the number of falls was assessed (a) at baseline (pre), referring to the last 6 months, and (b) weekly during chemotherapy via telephone calls.

Demographic, clinical and behavioural data (including minutes of exercise per week [28]) were collected from medical records and studyspecific forms. Relative dose intensity (RDI) and relative cumulative dose were calculated according to guidelines [32]. Concomitant CIPN prevention and treatment measures (e.g. cryotherapy, duloxetine intake) were queried from the patients.

Exercise adherence and tolerability. Based on training documents completed by the patients, adherence data were evaluated [33]. The reasons for missed training sessions and training-related adverse events were queried in weekly telephone calls.

\section{Exercise interventions}

Sensorimotor exercise training. The SMT was scheduled $3 \times /$ week for 35 min each. During an introductory one-to-one training session, the patients received a catalogue of exercises, including 45 illustrated exercise cards, and necessary training materials (e.g. Airex balance pad). The patients exercised either at home or in an open supervised training session at the NCT. Each exercise was carried out $3 \times 30 \mathrm{~s}$ with at least $30 \mathrm{~s}$ pause between sets. Patients were asked to progress their training based on individually perceived difficulty. Figure S1 and Table S1a provide further details.

Resistance training. The RT included a machine-based RT 2x/week for 45 min each, and a 15 min home-based training once a week. The detailed training descriptions can be found in Table S1b. Briefly, the machine-based RT consisted of a maximum of eight exercises per session and was performed in an experienced exercise oncology training facility (OnkoAktiv Network). After two familiarisation sessions, a one-repetition-maximum strength test (1RM) was conducted at each resistance machine. Its results were used to define initial training weights based on current guidelines (70-80\% 1RM) [34]. The home-based RT consisted of progressively designed core stability exercises.

Usual care. The control group received usual care (UC) without additional information about physical activity. During follow-up (post ${ }_{0}-$ post $_{6}$ ), UC patients had the opportunity to participate in one of the interventions described above for a maximum of 12 weeks.

All patients received weekly phone calls to monitor nutritional status (to identify the risk of malnutrition at an early stage) and fall history as well as training compliance and potential adverse events related to the intervention programme, if applicable.

\section{Statistical analysis}

The sample-size estimation was based on the main outcome criterion, the change of the TNSr from pre to post. Sample-size calculation was performed by Monte-Carlo simulations of the power for the Kruskal-Wallis Test. Simulations were performed with the following input parameters: (i) equal allocation between the three groups, (ii) equidistant population means, (iii) normalised equal distribution, (iv) $a=5 \%$. Under these assumptions, a sample size of 246 (82 per group) was calculated to achieve a power of $80 \%$. Assuming a maximal drop-out rate of $20 \%$, it was planned to recruit 300 patients.

Baseline differences were tested by Kruskal-Wallis or Chi²/Fisher's exact test in the case of categorical variables. The primary analyses followed an intention-to-treat (ITT) approach. Secondary analyses included a perprotocol (PP) approach where patients with an attendance rate of lower than $66.67 \%$ of planned training sessions were excluded from analyses [35]. In addition, a second exploratory $\mathrm{PP}_{\mathrm{Ex}}$ analyses with both exercise groups combined (only adherent exercisers; EX) vs. UC was conducted. The combination of the two intervention groups was substantiated due to comparable neuromuscular training adaptations [36]. Analysis of covariance (ANCOVA) was used to test (i) intervention effects (pre-post ${ }_{0}$ ), and (ii) changes during follow-up (post ${ }_{0}-$ post $_{3}$, post ${ }_{0}-$ post $_{6}$ ) with the change scores of the respective comparison being the dependent variable, the intervention groups (SMT vs. RT vs. UC; EX vs. UC) as independent variable and stratification variables (gender and treatment), age, and baseline

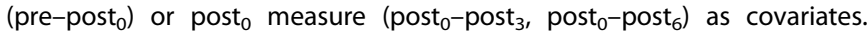
ANCOVA was based on complete case analyses per analysed study period (pre-post ${ }_{0}$, post $_{0}-$ post $_{3}$, post ${ }_{0}-$ post $_{6}$ ). The analysed sample size is indicated per variable and analysis. No adjustments for multiple comparisons for the follow-up comparisons and secondary outcomes and analyses were made, as these were considered to be explorative. Standardised effect sizes (ES) were calculated for within-group and between-group comparisons for all outcomes by respectively dividing the adjusted mean change or the adjusted between-group difference by the baseline standard deviation. For ease of presentation of the betweengroup comparisons, ES received a positive sign if it was in favour of the first group of the following comparisons: SMT vs. UC, RT vs. UC, SMT vs. RT, and EX vs. UC. All statistical tests were two-sided, and $P<0.05$ was considered statistically significant. SAS Enterprise Guide 7.1 (SAS Institute Inc., USA) was used for all analyses.

\section{RESULTS}

One hundred and seventy patients (mean age 53.3 years) were randomised after baseline testing, of which $N=159$ completed the intervention period and were included in the ITT analysis (Fig. 2). Most patients were female (85\%) and had breast cancer (74\%) (Table 2 and Table S2). Due to a poor recruitment rate (25\%), we were unable to achieve our intended sample size within the given project time.

\section{Adherence to the interventions}

Table S1a and S1b provide detailed information about exercise adherence. Briefly, the mean intervention length was 20 weeks for both groups. Mean attendance rate was $55 \%$ in the SMT and $49 \%$ in the RT group. The reasons for missed training sessions are listed in Table S3. Thirty-five patients were classified as adherent and included in PP/PP $P_{\mathrm{Ex}}$ analyses (SMT: $N=20, \mathrm{RT}: N=15$ ). Nonadherent patients had lower physical and cognitive function as well as higher fatigue and insomnia baseline values on the EORTC QLQ-C30 subscales (all $P<0.024$, Table S4).

Twenty-three patients reported mild training associated adverse events without indication for medical treatment (SMT: $N=10$ (21\%), RT: $N=13$ (25\%); see Table S5 for details). 


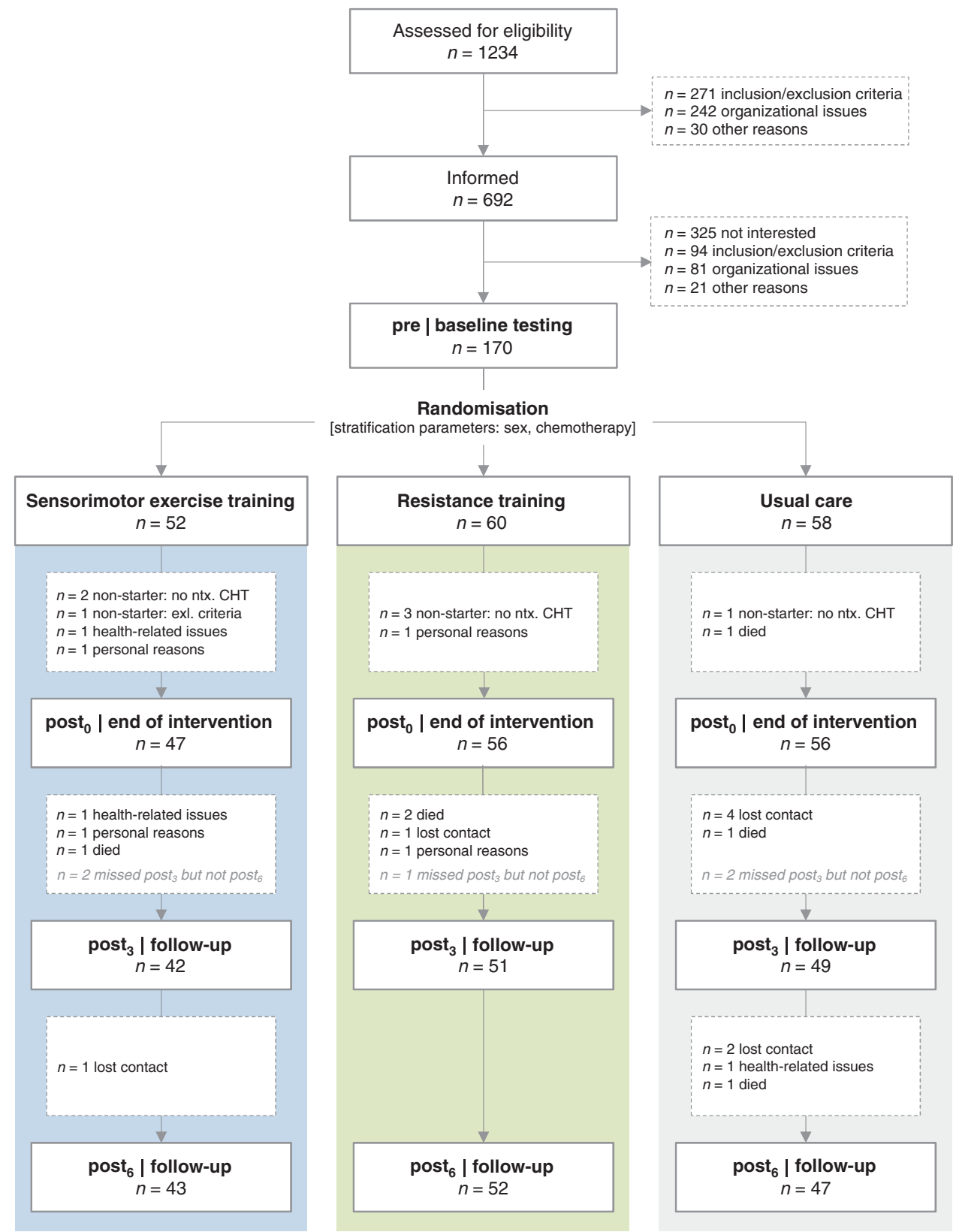

Fig. 2 CONSORT flow chart. Pre assessment point before neurotoxic chemotherapy, posto assessment point 3 weeks after neurotoxic chemotherapy, post $_{3}$ assessment point three months after post ${ }_{0}$, post $_{6}$ assessment point six months after post ${ }_{0}$.

During follow-up, $26 \%$ of the UC patients started a structured training: SMT $(N=6$, mean attendance rate: $62.0 \%$, range: 22.2-92.9\%), RT ( $N=7$, mean attendance rate: $41.5 \%$, range 23.1-64.3\%), or endurance training ( $N=1$, attendance rate: $100 \%)$. Of these patients, only $n=4$ (SMT $n=3$, endurance training $n=1$ ) were classified as "adherent" (at least $66.67 \%$ attendance rate). Reported exercise minutes per week increased descriptively in this

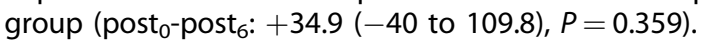

\section{CIPN signs and symptoms}

Table 3 provides summarised data for CIPN signs/symptoms revealed by ITT analyses. Complementary values (e.g. analysed number of participants, ES for within-group comparisons), as well as results of secondary outcomes and complete PP/PP $\mathrm{EX}_{\text {analyses, }}$ are presented in Table S6.

Overall, the TNSr score increased significantly in all three groups during chemotherapy with small, non-significant between-group differences; comparable results were found for the TNS variations (TNSC, TNSm) and NCS parameters (ITT, Table 3). PP/PPEX analyses provided comparable results with larger effect sizes (Fig. 3).

During the intervention period, between-group comparisons of the increased EORTC CIPN-15 total and sub-scores revealed no significant differences between groups (ITT). PP $\mathrm{EX}_{\mathrm{EX}}$ analysis showed a significant between-group comparison in favour of EX regarding sensory symptoms in the feet $\left(\mathrm{PP}_{\mathrm{EX}}\right.$ pre-post ${ }_{0}: P=$ $0.039, \mathrm{ES}=-1.27$ )

During follow-up, TNSr and its variations, as well as NCS parameters, did not change according to inferential statistics. EORTC CIPN-15 total score revealed a significant decrease in SMT and RT (ITT post - post $_{6}: P<0.038$ ) and for symptoms in the hands for all groups (ITT post $_{0}-$ post $_{6}: P<0.045$ ). Between-group comparisons revealed marginal, non-significant differences with overall small effect sizes during the follow-up periods. $\mathrm{PP}$ and $\mathrm{PP}_{\mathrm{EX}}$ analyses showed overall comparable results. 
Table 2. Patient characteristics.

\begin{tabular}{|c|c|c|c|c|c|}
\hline & Total & SMT & RT & UC & $P$ value \\
\hline \multicolumn{6}{|l|}{ Demographic profile } \\
\hline Number of patients $(n)$ & $163(100 \%)$ & $49(30 \%)$ & $57(35 \%)$ & $57(35 \%)$ & - \\
\hline Number of female patients $(n)$ & $138(85 \%)$ & $41(84 \%)$ & $48(84 \%)$ & $49(86 \%)$ & 0.942 \\
\hline Age (years, mean $\pm S D$ ) & $53.3 \pm 11.5$ & $51.7 \pm 10.8$ & $53.4 \pm 11.7$ & $54.5 \pm 11.9$ & 0.396 \\
\hline Married $(n(\%))$ & $124(78 \%)$ & $38(78 \%)$ & $43(78 \%)$ & $43(78 \%)$ & 0.996 \\
\hline University degree $(n(\%))$ & $54(34 \%)$ & $22(45 \%)$ & $15(27 \%)$ & $17(31 \%)$ & 0.140 \\
\hline \multicolumn{6}{|l|}{ Medical profile } \\
\hline Height $(\mathrm{cm}$, mean \pm SD) & $167.3 \pm 6.8$ & $168.5 \pm 7.5$ & $167.5 \pm 6.7$ & $166 \pm 6$ & 0.241 \\
\hline Weight $(\mathrm{kg}$, mean $\pm \mathrm{SD})$ & $72.9 \pm 14.3$ & $74.2 \pm 15.7$ & $74.8 \pm 13.3$ & $70 \pm 13.7$ & 0.108 \\
\hline BMI $\left(\mathrm{kg} / \mathrm{m}^{2}\right.$, mean $\left.\pm S D\right)$ & $26.1 \pm 5$ & $26.2 \pm 5.6$ & $26.7 \pm 4.7$ & $25.4 \pm 4.8$ & 0.272 \\
\hline \multicolumn{6}{|l|}{ Comorbidities ( $n(\%))$} \\
\hline None & $21(13 \%)$ & $9(18 \%)$ & $4(7 \%)$ & $8(14 \%)$ & 0.209 \\
\hline Cardiovascular & $60(37 \%)$ & $19(39 \%)$ & $20(35 \%)$ & $21(37 \%)$ & 0.926 \\
\hline Musculoskeletal & $94(58 \%)$ & $22(45 \%)$ & $40(70 \%)$ & $32(56 \%)$ & 0.030 \\
\hline Neurological & $14(9 \%)$ & $3(6 \%)$ & $7(12 \%)$ & $4(7 \%)$ & 0.537 \\
\hline Endocrine/metabolic & $21(13 \%)$ & $7(14 \%)$ & $10(18 \%)$ & $4(7 \%)$ & 0.230 \\
\hline [diabetes] & $7(4 \%)$ & $2(4 \%)$ & $3(5 \%)$ & $2(4 \%)$ & 1.00 \\
\hline Psychiatric & $9(6 \%)$ & $3(6 \%)$ & $3(5 \%)$ & $3(5 \%)$ & 1.00 \\
\hline Prior cancer diagnosis ${ }^{a}$ & $20(12 \%)$ & $7(14 \%)$ & $3(5 \%)$ & $10(18 \%)$ & 0.119 \\
\hline \multicolumn{6}{|l|}{ Oncological diagnosis ( $n(\%)$ ) } \\
\hline Breast cancer & $121(74 \%)$ & $36(73 \%)$ & $41(72 \%)$ & $44(77 \%)$ & $0.805^{\mathrm{b}}$ \\
\hline Pancreatic cancer & $9(6 \%)$ & $2(4 \%)$ & $3(5 \%)$ & $4(7 \%)$ & \\
\hline Prostate cancer & $5(3 \%)$ & $2(4 \%)$ & & $3(5 \%)$ & \\
\hline Stomach cancer & $5(3 \%)$ & $2(4 \%)$ & $2(4 \%)$ & $1(2 \%)$ & \\
\hline Oesophagus cancer & $4(2 \%)$ & $1(2 \%)$ & $1(2 \%)$ & $2(4 \%)$ & \\
\hline Colon cancer & $4(2 \%)$ & $3(6 \%)$ & $1(2 \%)$ & & \\
\hline Brain cancer & $3(2 \%)$ & & $3(5 \%)$ & & \\
\hline Ovary cancer & $3(2 \%)$ & $1(2 \%)$ & $1(2 \%)$ & $1(2 \%)$ & \\
\hline Tongue base cancer & $2(1 \%)$ & & $1(2 \%)$ & $1(2 \%)$ & \\
\hline Rectal cancer & $2(1 \%)$ & & $1(2 \%)$ & $1(2 \%)$ & \\
\hline Anus/anal canal cancer & $1(1 \%)$ & & $1(2 \%)$ & & \\
\hline Bronchus/lung cancer & $1(1 \%)$ & & $1(2 \%)$ & & \\
\hline Cervix uteri cancer & $1(1 \%)$ & & $1(2 \%)$ & & \\
\hline Bladder cancer & $1(1 \%)$ & $1(2 \%)$ & & & \\
\hline Malignant neoplasm without specification of site & $1(1 \%)$ & $1(2 \%)$ & & & \\
\hline Disease status (UICC) $(n(\%))$ & & & & & 0.933 \\
\hline $1 / I I$ & $102(65 \%)$ & $30(67 \%)$ & $36(63 \%)$ & $36(64 \%)$ & \\
\hline III/IV & $56(35 \%)$ & $15(33 \%)$ & $21(37 \%)$ & $20(36 \%)$ & \\
\hline \multicolumn{6}{|l|}{ Chemotherapy } \\
\hline Duration (weeks, mean \pm SD) & $17.2 \pm 5.3$ & $17.0 \pm 5.2$ & $16.7 \pm 5.1$ & $17.8 \pm 5.7$ & 0.672 \\
\hline Time between last chemotherapy and post ${ }_{0}$ (days, mean \pm SD) & $22.9 \pm 9.2$ & $22.0 \pm 9.3$ & $23.5 \pm 8.9$ & $23.0 \pm 9.4$ & 0.411 \\
\hline Taxane-based $(n(\%))$ & $87(53 \%)$ & $27(55 \%)$ & $30(53 \%)$ & $30(53 \%)$ & $0.961^{c}$ \\
\hline Taxane-platinum combination $(n(\%))$ & $52(32 \%)$ & $15(31 \%)$ & $18(32 \%)$ & $19(33 \%)$ & \\
\hline Platinum-based $(n(\%))$ & $19(12 \%)$ & $7(14 \%)$ & $6(11 \%)$ & $6(11 \%)$ & \\
\hline Vinca alkaloid $(n(\%))$ & $4(2 \%)$ & & $3(5 \%)$ & $1(2 \%)$ & \\
\hline Platinum-vinca alkaloid combination ( $n(\%))$ & $1(1 \%)$ & & & $1(2 \%)$ & \\
\hline \multicolumn{6}{|l|}{ Relative dose intensity } \\
\hline Relative dose intensity $(\%$, mean $\pm S D$ ) & $93.2 \pm 8.6$ & $94.5 \pm 8.4$ & $93.1 \pm 8$ & $92.2 \pm 9.4$ & 0.461 \\
\hline min. $85 \%$ of planned dose intensity $(n(\%))$ & $124(85 \%)$ & $41(93 \%)$ & $44(81 \%)$ & $39(81 \%)$ & 0.187 \\
\hline Relative cumulative dose $(\%$, mean $\pm S D)$ & $93.9 \pm 10.6$ & $93.7 \pm 12.7$ & $93.9 \pm 8.8$ & $94.2 \pm 10.4$ & 0.395 \\
\hline min. $85 \%$ of planned dose $(n(\%))$ & $121(81 \%)$ & $38(84 \%)$ & $44(81 \%)$ & $39(78 \%)$ & 0.723 \\
\hline \multicolumn{6}{|l|}{ Behavioural profile } \\
\hline Smoking $(n(\%))$ & & & & & 0.378 \\
\hline Never smoker & $66(42 \%)$ & $18(37 \%)$ & $27(50 \%)$ & $21(38 \%)$ & \\
\hline Former smoker & $63(40 \%)$ & $19(39 \%)$ & $18(33 \%)$ & $26(47 \%)$ & \\
\hline Current smoker & $29(18 \%)$ & $12(24 \%)$ & $9(17 \%)$ & $8(15 \%)$ & \\
\hline Alcohol consumption (WHO) $(n(\%))$ & & & & & 0.697 \\
\hline Non-drinker ( $0 \mathrm{~g} /$ day) & $42(26 \%)$ & $12(24 \%)$ & $12(22 \%)$ & $18(33 \%)$ & \\
\hline Harmless use (f: $\leq 12 \mathrm{~g} /$ day, $\mathrm{m}: \leq 24 \mathrm{~g} /$ day) & $94(59 \%)$ & $29(59 \%)$ & $34(62 \%)$ & $31(56 \%)$ & \\
\hline Harmful use (f: $>12$ g/day, m: $>24$ g/day) & $23(14 \%)$ & $8(16 \%)$ & $9(16 \%)$ & $6(11 \%)$ & \\
\hline
\end{tabular}

post $_{0}$ assessment point at the completion of neurotoxic chemotherapy.

Bold $P$ values are considered statistically significant different $(P<0.05)$.

${ }^{a}$ No patients were included who already showed CIPN symptoms (see exclusion criteria).

${ }^{b}$ Breast cancer vs. others.

${ }^{c}$ Chemotherapy containing taxanes vs. others. 


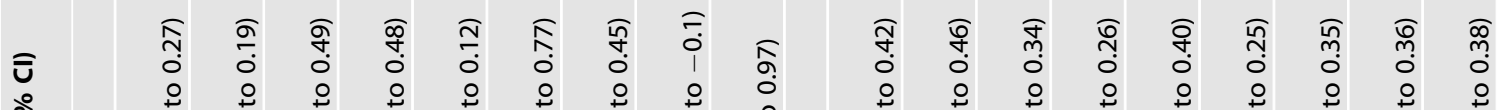

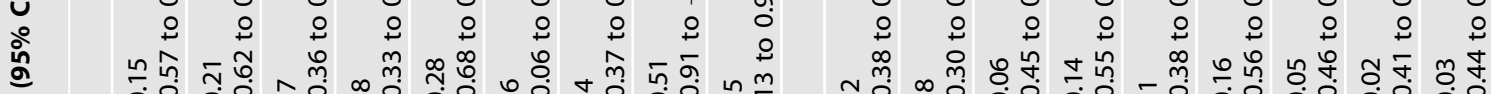

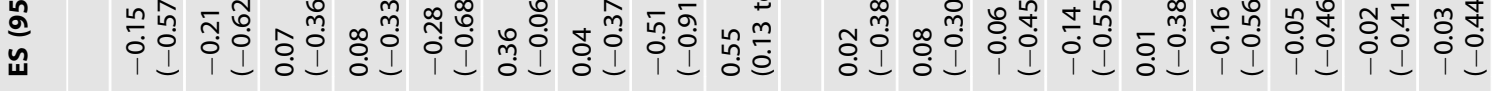

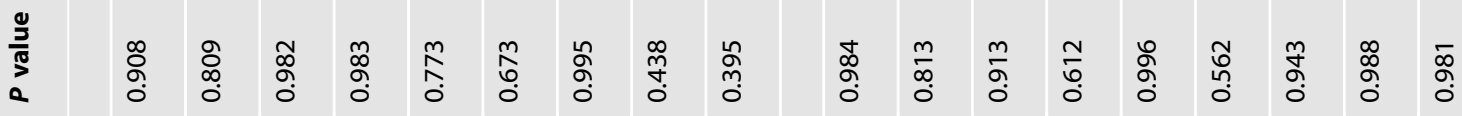

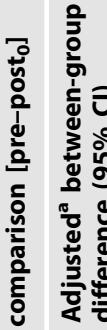

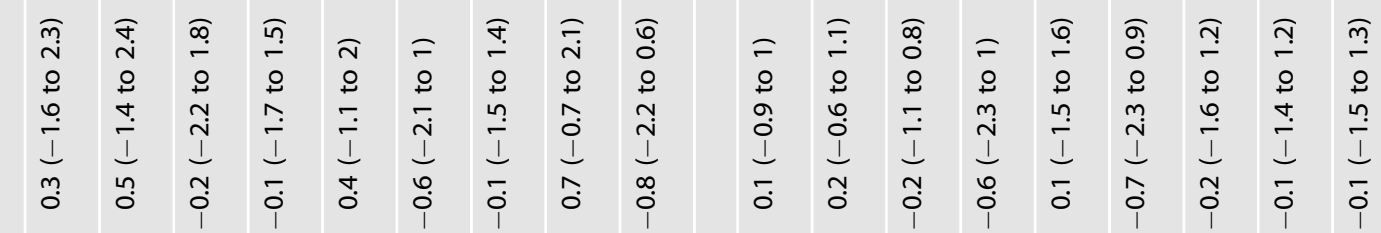

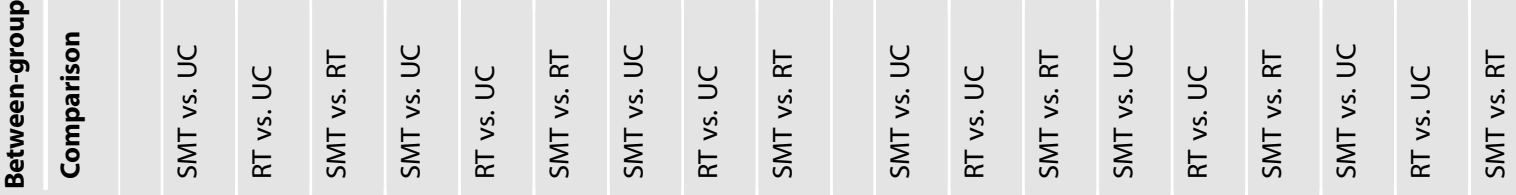

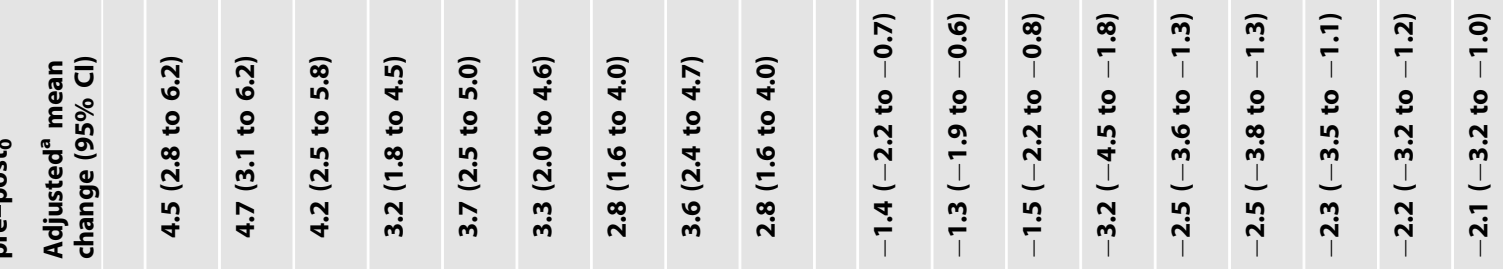

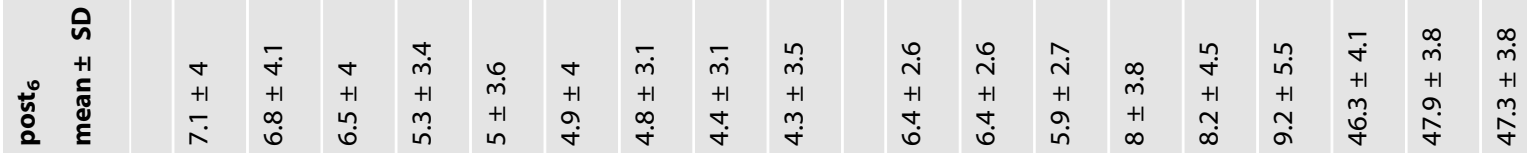

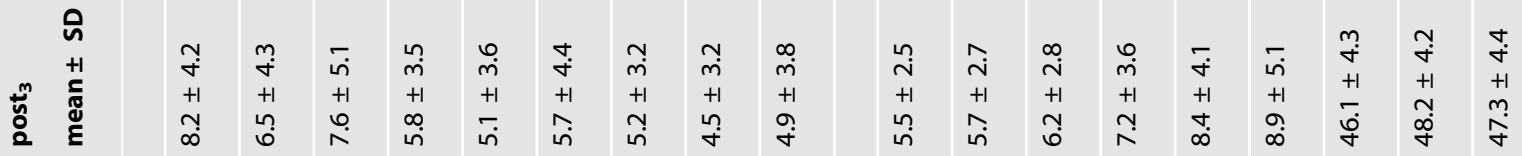

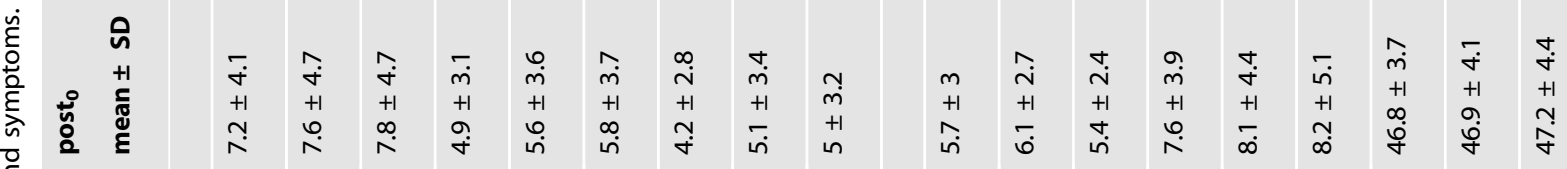

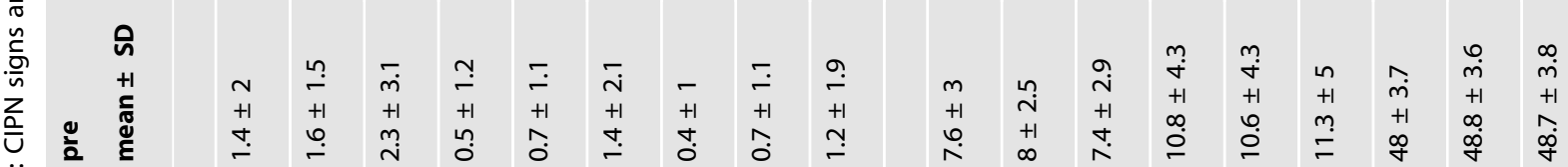

ํํㄴ

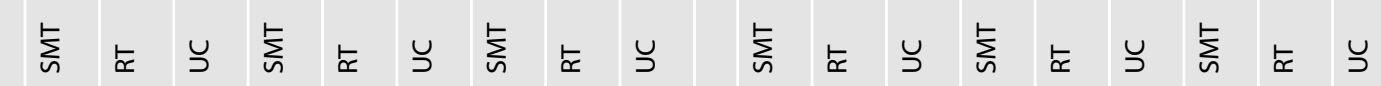
๘ัّ
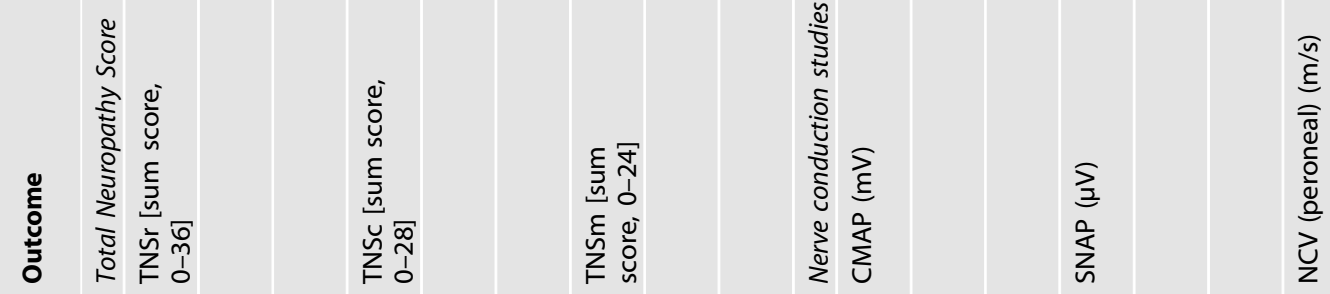


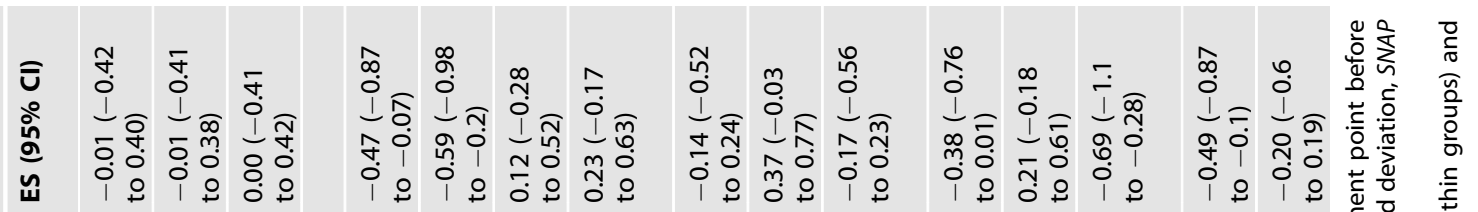

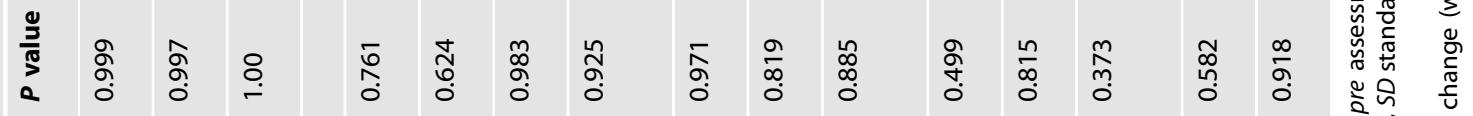

家

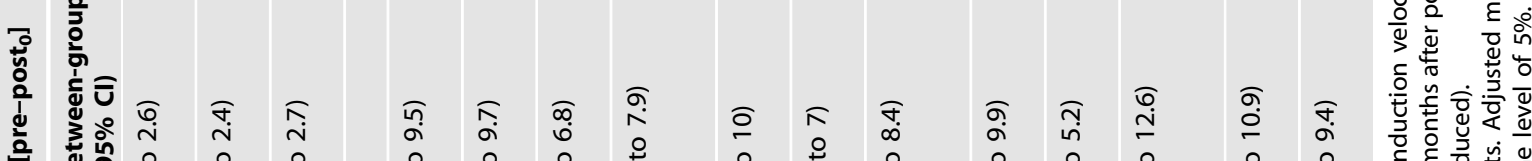

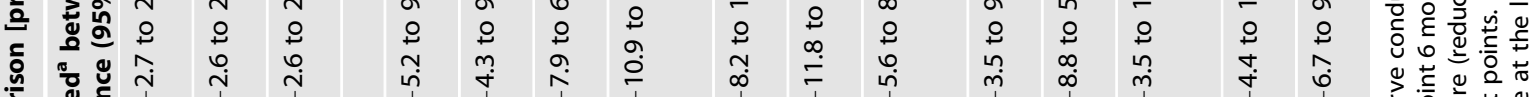

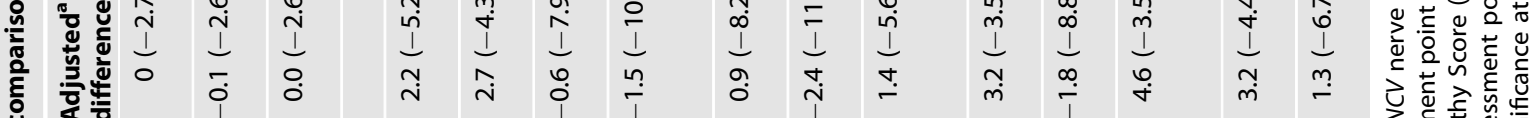

告

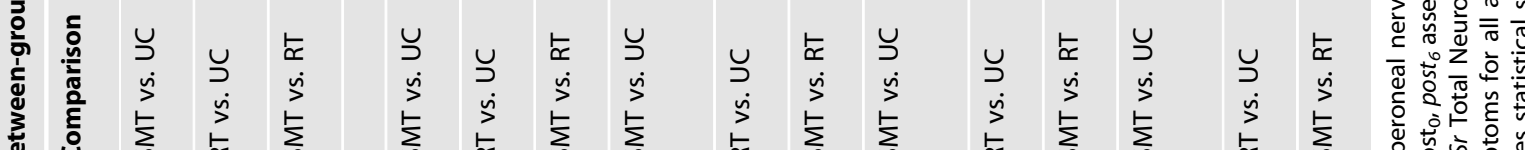

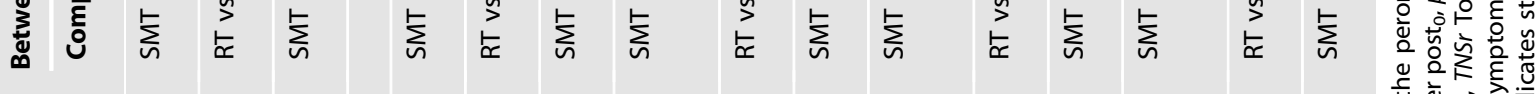

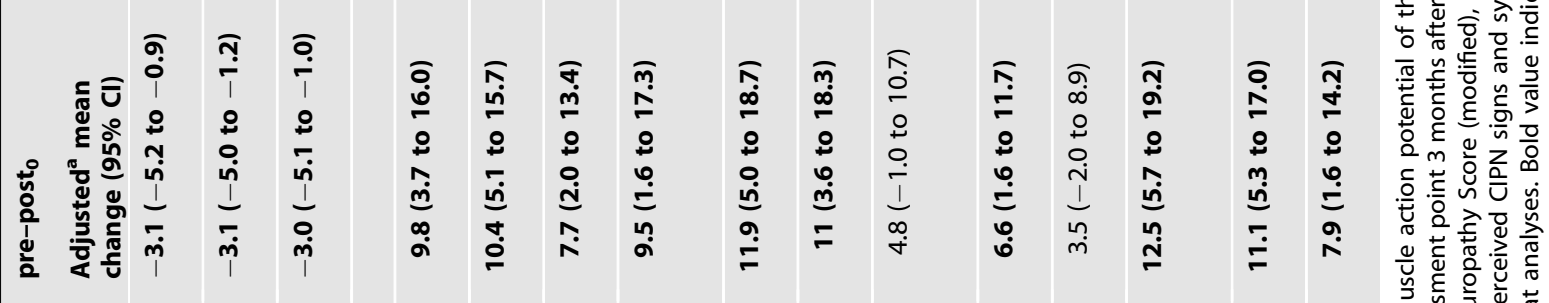

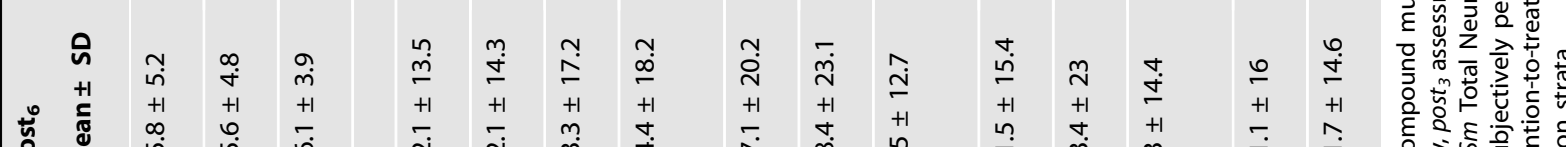

घ

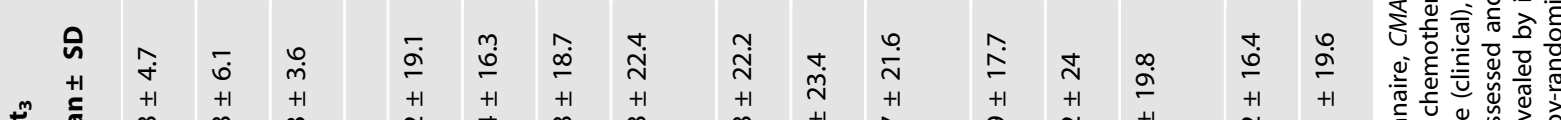

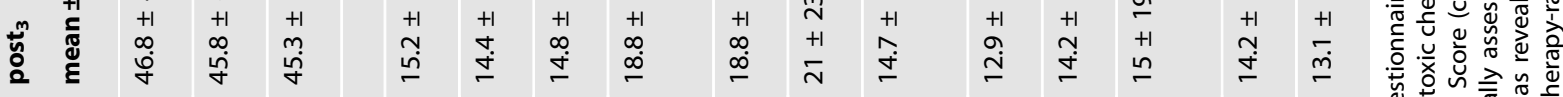

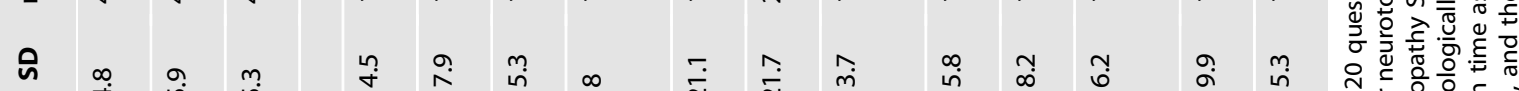

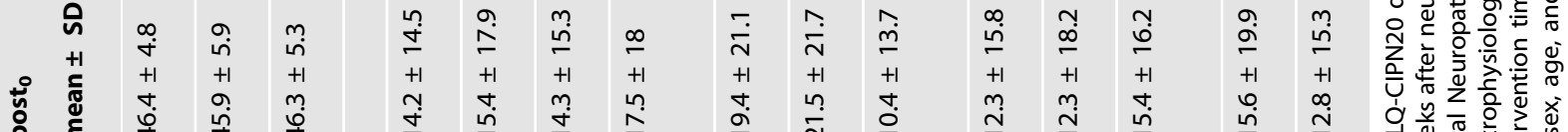

2 $\quad$ \&

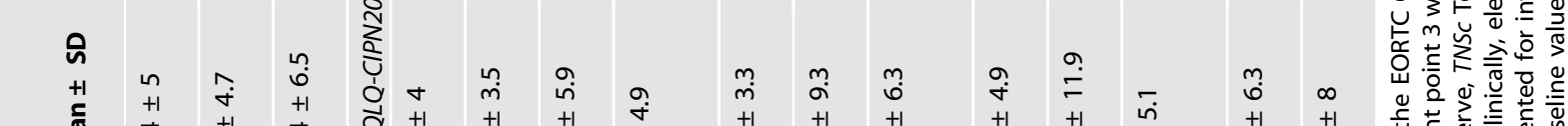

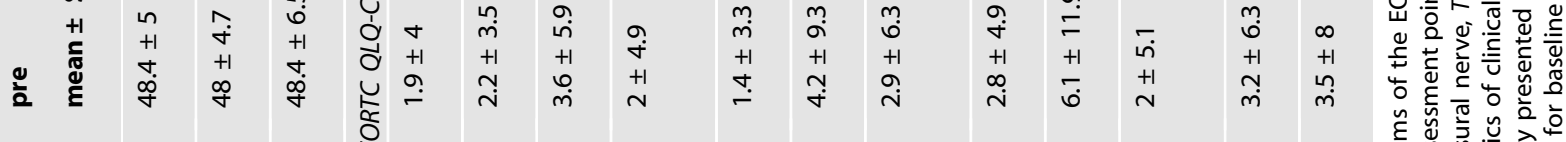

O $\quad$ 出

总

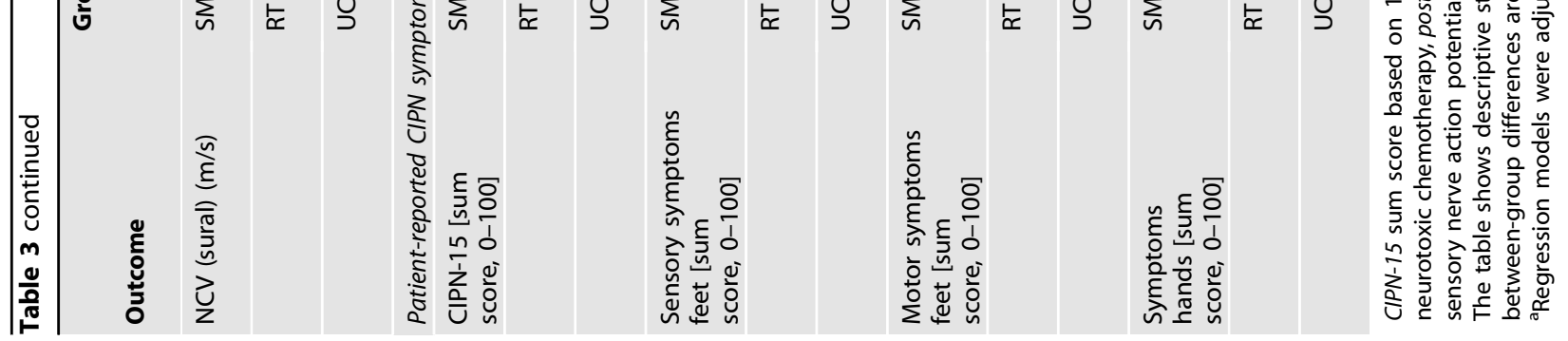




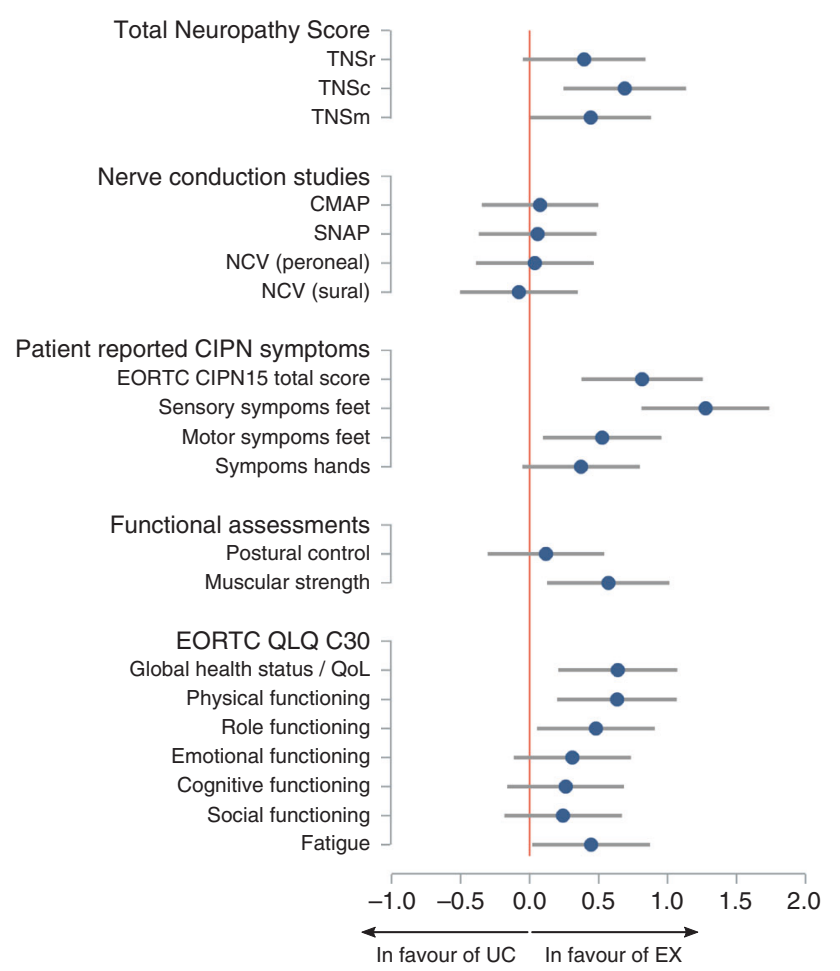

Fig. 3 Effect sizes for CIPN signs and symptoms and other symptoms associated with anticancer therapy (pre-post ${ }_{0}, \mathrm{PP}_{\mathrm{EX}}$ analysis). CMAP compound muscle action potential of peroneal nerve, NCV nerve conduction velocity, QoL quality of life, SNAP sensory nerve action potential of sural nerve, TNSC Total Neuropathy Score (clinical), TNSm Total Neuropathy Score (modified), TNSr Total Neuropathy Score (reduced).

\section{Functional assessments}

$\mathrm{COP}$ mean velocity in $\mathrm{BP}_{\mathrm{EC}}$ increased significantly during the

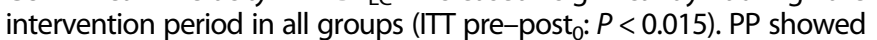
a tendency towards unchanged adjusted mean change values for SMT (pre-post 0 : $P=0.235$ ). For all analyses approaches, betweengroup differences were non-significant with small effect sizes. During follow-up, all groups showed decreased COP mean velocities (ITT post $_{0}-$ post $_{6}: P<0.019$ ), however, this effect only remained significant for the SMT group in both PP analyses. Between-group differences were non-significant and had small effect sizes for all analyses.

In all analyses approaches, mean $\mathrm{MP}_{\mathrm{EO}}$ standing time remained unchanged for SMT and RT, but significantly decreased in UC, resulting in a significant between-group comparison for ITT analysis in favour of both exercise groups (pre-post ${ }_{0}$ : SMT vs. UC $P=0.045$, ES $=0.27$; RT vs. UC $P=0.023$, ES $=0.28$ ). During follow-up, comparisons did not reveal any significant differences (ITT, PP, PP $\mathrm{EX}_{\text {). }}$

RT and SMT sustained their baseline muscle strength status while UC showed decreased values (ITT pre-post $0: P=0.016$ ). PP analyses revealed a significant gain of muscle strength for RT (pre-post ${ }_{0}: P=0.003$ ) and $\mathrm{PP}_{\mathrm{EX}}$ analysis for adherent $\mathrm{EX}$ (pre-post $0: P=0.027$ ). Consequently, between-group comparisons revealed a significant difference in favour of RT compared to UC (pre-post $_{0}$ : ITT $P=0.045, \mathrm{ES}=0.30$; $\mathrm{PP} P<0.001, \mathrm{ES}=0.81$ ) as well

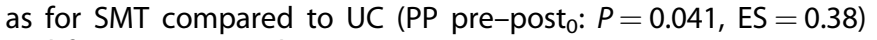
and for EX compared to UC ( $P_{E X}$ pre-post $\left._{0}: P<0.001, E S=0.57\right)$. During follow-up, no significant between-group comparisons and overall small effect sizes were found.

\section{Patient-reported outcomes}

During the intervention period, primary ITT analyses of the EORTC QLQ-C30 scores revealed non-significant between-group differences and mainly small effect sizes. However, PP analyses showed significant group differences between RT and UC for global health status (pre-post $0: P=0.018, E S=0.85$ ) and social functioning (pre-post $0: P=0.047, \mathrm{ES}=0.52$ ). $\mathrm{PP}_{\mathrm{EX}}$ analyses additionally showed significant between-group differences in favour of adherent EX for physical functioning (pre-post $0: P=0.014, \mathrm{ES}=0.63$ ), role function-

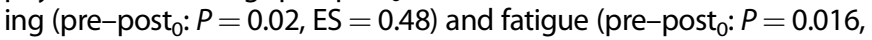

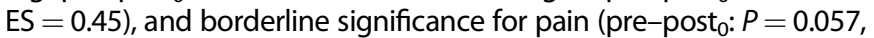
$E S=0.32$ ). Overall, the follow-up period revealed mainly nonsignificant between-group comparisons with small effect sizes for all analyses approaches.

Fear of falling increased in UC during chemotherapy (ITT pre-post ${ }_{0}: P=0.037, \mathrm{ES}=0.57$ ), but not in SMT and RT. However, pre-post $_{0}$ changes did not differ between groups in all analyses approaches, nor did the number of falls during the intervention period (see Table S7 for details).

\section{Chemotherapy completion rate}

In the ITT study sample, chemotherapy dose reductions and early terminations were evenly distributed between groups and most often associated with CIPN symptoms (Table S8). Mean RDI did not differ between study groups (ITT $P=0.461$, Table 2; PP: SMT $97.3 \pm 3.8$, RT 95.7 \pm 6.0 , UC 92.2 $\pm 9.4 ; P=0.103)$, except when comparing EX with UC (PP $\mathrm{EX}_{\text {: }}$ EX: $96.6 \pm 4.8$, UC: $92.2 \pm 9.4 ; P=$ 0.045 ). So did the clinically relevant threshold of $85 \%$ RDI (EX: $94 \%$, UC: $76 \% ; P=0.032$ ). Concomitant CIPN prevention or treatment measures did not differ between groups (Table S8).

\section{DISCUSSION}

The PIC study aimed to investigate the preventive effect of sensorimotor exercise training (SMT) or resistance training (RT) versus usual care (UC) on CIPN during neurotoxic chemotherapy. Our primary ITT analysis revealed that none of the exercise programmes was able to impact the progression of neurologically objectified and patient-reported CIPN signs/symptoms. Due to the high numbers of missed training sessions in both groups, we excluded non-adherent patients for exploratory per-protocol analyses. Subjectively perceived sensory symptoms in the feet increased less during chemotherapy in the adherent exercisers (pooled group: SMT+RT) compared to UC. Furthermore, compliance to chemotherapy was found to be enhanced in this group. On the functional level, we identified a better course of muscular strength in favour of the adherent exercisers, as well as better results in terms of overall quality of life, physical and role functioning, fatigue, and a trend-level effect for pain.

Only a few RCTs have investigated the preventive effect of exercise on CIPN during neurotoxic chemotherapy [16-21], of which only two used clinical instruments to assess CIPN symptoms $[16,19]$. In accordance with our ITT results, Bland et al. [19] did not demonstrate an intervention effect of a multimodal exercise programme during taxane-based chemotherapy with regard to quantitative sensory tests (deep sensitivity: tuning fork; pain: pinprick). In contrast, a sub-analysis of a comparable exercise programme showed a reduction of CIPN symptoms by tuning fork evaluation in the intervention group but not in the control group [16].

Similarly, the results of the other studies regarding subjectively perceived CIPN symptoms are largely consistent with our ITT analyses. The studies which used psychometrically tested questionnaires, that focus on CIPN symptoms in the whole body, were not able to find a significant intervention effect (EORTC QLQCIPN15 [19]) or only observed a trend-level effect (FACT/GOG-Ntx [20]). Kleckner et al. [17] used a numeric-rating-scale (NRS 0-10), which only focused on two symptom combinations in hands and feet. The authors reported a trend-level effect for the perception of numbness/tingling and a significant intervention effect for hot/ coldness in favour of the intervention group. Comparable results 
were observed for adherent exercisers within our $\mathrm{PP}_{\mathrm{EX}}$ analysis, who developed less sensory symptoms in the feet during chemotherapy compared to UC. A sub-analysis by Bland et al. [19] mirrors these findings by showing that multimodal exercise can prevent the progression of moderate-to-severe numbness in toes and feet within the first three taxane cycles. Based on the studies cited, it could be hypothesised that a preventive effect for CIPN signs and symptoms can only be detected in the body regions that are targeted by the training implemented, e.g. due to neural adaptations [37], release of neurotrophic factors [38] or reduced inflammation processes [39]. In our opinion, this is a highly relevant finding, since CIPN-induced dose modifications of chemotherapy are mainly based on patients' subjective perception. Therefore, the better chemotherapy tolerance (mean RDI) observed in the adherent exercisers (97\%) compared to UC (92\%) may be associated with the shown lower perceived CIPN symptoms in this group. Although the evidence does not yet allow final conclusions to be drawn as to whether exercise actually has a positive influence on chemotherapy tolerance [40], these findings are in line with Bland et al. [19] and point towards a promising direction.

\section{Functional status and patient-reported outcomes}

Various studies have shown that neurotoxic chemotherapy can have a negative effect on postural control [28, 41,42], which may be partly prevented by a multimodal training programme [18]. Our COP data did not replicate this result and showed only a marginal trend in favour of the SMT group. Based on the mean standing time in $\mathrm{MP}_{\mathrm{EO}}$ position, however, SMT and RT showed a more favourable progression of postural control than UC. The improved standing time in the RT group during neurotoxic chemotherapy could have been achieved by increased muscle strength observed in the RT-adherent patients [43]. Since cancer patients normally show a chemotherapy-induced deterioration of muscle strength [44] -as also shown in our UC group-the increase but also the maintenance of muscle strength by RT or SMT is an important finding.

Although CIPN and associated poor postural stability are known to increase the risk of falling $[5,7]$, the fall prevalence of $8 \%$ in our total cohort during chemotherapy is markedly lower compared with another study showing annual fall rates of $43-57 \%$ after cancer treatment [45]. This difference might be explained by the higher age of these patients ( +10 years), but also by the longer time after diagnosis ( +6 years). In addition, an enhanced focus on locomotion in everyday life due to the acute change in sensory perception and generally less everyday activities during chemotherapy may further explain this difference. The latter point might also be in line with the majority of our patients (71\%) reporting low concerns about falling during chemotherapy (FES-I value <20) [46].

Finally, the adherent exercisers were able to enhance QoL during chemotherapy. The difference compared with UC $(+12.9$ points) can be seen as clinically meaningful [47], and is in accordance with Bland et al. [19]. In addition, we observed better results in favour of adherent exercisers in terms of physical and social functioning as well as fatigue and a trend-level effect for pain which are in line with a large body of exercise oncology studies [34].

\section{CIPN signs and symptoms during follow-up}

Neurologically objectified CIPN signs/symptoms did not change during the follow-up period of 6 months, whereas EORTC CIPN-15 total score decreased significantly in RT and SMT as well as CIPN symptoms in the hands in all groups. However, group means were still elevated compared to baseline values. These results are in line with many other studies addressing the long-term persistence of CIPN symptoms after completion of chemotherapy [48]. Structured exercise interventions helped to positively influence objectively assessed [10-12] and subjectively perceived CIPN signs/symptoms [10, 12-14]. However, the proportion of patients who followed a structured exercise programme within our study and their adherence were probably too small to show this effect.

\section{Limitations and future directions}

In comparison to most exercise intervention studies focusing on CIPN prevention, we provide the largest sample size for ITT and PP analyses with comprehensive and recommended CIPN diagnostics [49]. However, in line with Bland et al. [19], we were unable to achieve our target sample size and thus could not confirm our initial hypothesis through our primary ITT analyses. In addition to the lack of power, the high non-attendance rate in both exercise interventions, accompanied by a resulting insufficient training stimulus, could also explain the absence of an intervention effect. Therefore, we excluded non-adherent patients from analyses. Although most of the PP results show high effect sizes and are in line with other studies, these analyses are per se not confirmatory. Hence, the presented results need to be verified by future studies, not least to rule out a potential selection bias of the PP population, i.e. by showing that the higher training adherence and no other factors led to the intervention effects shown. Overall, future studies should amend the following aspects: (i) larger sample size of adherent exercisers, e.g. by means of measures to increase exercise adherence (see "Practical considerations"), (ii) focus on expanding recruitment to other entities, as most of our patients (and those in the other studies) had breast cancer and were female, which hampers generalisability, (iii) longer follow-up period with a larger sample size and comprehensive (device-based) physical activity monitoring, (iv) higher CIPN assessment density during chemotherapy in order to detect variations in the effectiveness of exercises [19] and consequently to be able to make adjustments and (v) modification of CIPN diagnostics towards several specifically tailored procedures that focus on the targeted training region instead of depicting the entire peripheral nerve status as our primary endpoint, TNSr. The latter point also implies the need for the validation of these modified CIPN assessments, as the results shown by us and Bland et al. [19] are based on a standardised questionnaire but not on psychometrically tested subscales.

\section{Practical considerations}

Based on our results and those of other authors $[16,17,19]$, it might be advisable to recommend a multimodal training approach to preventively influence as many facets of CIPN as possible. This multimodal training approach should consist of SMT and RT $[16,19]$, and possibly also endurance training $[16,17,19]$. However, this training approach can only be effective if an adequate training stimulus is achieved through sufficient exercise adherence. Almost half of the missed training sessions were due to side effects of anticancer treatment (e.g. nausea, vomiting, pain). It is conceivable that a temporary adjustment of the training (e.g. reduction of the duration and/or intensity) depending on the side effects that occurred may improve the training adherence. For example, Bland et al. [19] reduced the intensity of the supervised training in the first week after chemotherapy and were able to achieve a higher attendance rate $(78 \pm 23 \%)$. Nevertheless, some side effects will always require a (temporarily) abstinence from exercise (e.g. thrombosis). Therefore, it is even more important that patients miss as few training sessions as possible due to other reasons.

Approximately one-third of all missed training sessions in our study were based on time constraints and motivational issues. Adherence enhancing measures, which go beyond the conducted telephone calls and include well-founded behavioural change techniques, may additionally increase exercise adherence and thus the prevention effect in terms of perceived CIPN symptoms and functional limitations [50]. These might also help the non-adherent patients who had lower physical and cognitive function as well as 
higher fatigue and insomnia values at baseline compared to the adherent patients, to enhance their attendance rate.

\section{CONCLUSION}

SMT and/or RT might be effective strategies to prevent sensory CIPN symptoms in the feet during neurotoxic chemotherapy and enhance chemotherapy tolerance as well as QoL. However, as these results are based on PP analysis, future studies need to confirm these findings.

\section{DATA AVAILABILITY}

All raw data analysed for this publication can be made available on request.

\section{REFERENCES}

1. Molassiotis A, Cheng HL, Lopez V, Au JSK, Chan A, Bandla A, et al. Are we misestimating chemotherapy-induced peripheral neuropathy? Analysis of assessment methodologies from a prospective, multinational, longitudinal cohort study of patients receiving neurotoxic chemotherapy. BMC Cancer. 2019;19:132.

2. Stubblefield MD, Burstein HJ, Burton AW, Custodio CM, Deng GE, Ho M, et al. NCCN task force report: management of neuropathy in cancer. J Natl Compr Canc Netw. 2009;7:S7-8.

3. Cavaletti G, Alberti P, Argyriou AA, Lustberg M, Staff NP, Tamburin S. Chemotherapy-induced peripheral neurotoxicity: a multifaceted, still unsolved issue. J Peripher Nerv Syst. 2019;24:S6-12.

4. Greenlee H, Hershman DL, Shi Z, Kwan ML, Ergas IJ, Roh JM, et al. BMI, lifestyle factors and taxane-induced neuropathy in breast cancer patients: the pathways study. J Natl Cancer Inst. 2017;109:1-8.

5. Bao T, Basal C, Seluzicki C, Li SQ, Seidman AD, Mao JJ. Long-term chemotherapyinduced peripheral neuropathy among breast cancer survivors: prevalence, risk factors, and fall risk. Breast Cancer Res Treat. 2016;159:327-33.

6. Ezendam NP, Pijlman B, Bhugwandass C, Pruijt JF, Mols F, Vos MC, et al. Chemotherapy-induced peripheral neuropathy and its impact on health-related quality of life among ovarian cancer survivors: results from the population-based PROFILES registry. Gynecol Oncol. 2014;135:510-7.

7. Fino PC, Horak FB, El-Gohary M, Guidarelli C, Medysky ME, Nagle SJ, et al. Postural sway, falls, and self-reported neuropathy in aging female cancer survivors. Gait Posture. 2019;69:136-42.

8. Varedi M, Lu L, Howell CR, Partin RE, Hudson MM, Pui $C H$, et al. Peripheral neuropathy, sensory processing, and balance in survivors of acute lymphoblastic leukemia. J Clin Oncol. 2018;36:2315-22.

9. Hershman DL, Lacchetti C, Dworkin RH, Lavoie Smith EM, Bleeker J, Cavaletti G, et al. Prevention and management of chemotherapy-induced peripheral neuropathy in survivors of adult cancers: American Society of Clinical Oncology clinical practice guideline. J Clin Oncol. 2014;32:1941-67.

10. Kneis S, Wehrle A, Müller J, Maurer C, lhorst G, Gollhofer A, et al. It's never too late -balance and endurance training improves functional performance, quality of life, and alleviates neuropathic symptoms in cancer survivors suffering from chemotherapy-induced peripheral neuropathy: results of a randomized controlled trial. BMC Cancer. 2019;19:414-24.

11. Streckmann F, Lehmann HC, Balke M, Schenk A, Oberste M, Heller A, et al. Sensorimotor training and whole-body vibration training have the potential to reduce motor and sensory symptoms of chemotherapy-induced peripheral neuropathy-a randomized controlled pilot trial. Support Care Cancer. 2019;27:2471-8.

12. Schönsteiner SS, Bauder Mißbach H, Benner A, Mack S, Hamel T, Orth M, et al. A randomized exploratory phase 2 study in patients with chemotherapy-related peripheral neuropathy evaluating whole-body vibration training as adjunct to an integrated program including massage, passive mobilization and physical exercises. Exp Hematol Oncol. 2017;6:5.

13. Zimmer P, Trebing S, Timmers-Trebing U, Schenk A, Paust R, Bloch W, et al. Eightweek, multimodal exercise counteracts a progress of chemotherapy-induced peripheral neuropathy and improves balance and strength in metastasized colorectal cancer patients: a randomized controlled trial. Support Care Cancer. 2018;26:615-24.

14. Dhawan $S$, Andrews R, Kumar L, Wadhwa S, Shukla G. A randomized controlled trial to assess the effectiveness of muscle strengthening and balancing exercises on chemotherapy-induced peripheral neuropathic pain and quality of life among cancer patients. Cancer Nurs. 2020;43:269-80.

15. Schwenk M, Grewal GS, Holloway D, Muchna A, Garland L, Najafi B. Interactive sensor-based balance training in older cancer patients with chemotherapy- induced peripheral neuropathy: a randomized controlled trial. Gerontology. 2016;62:553-63.

16. Streckmann F, Kneis S, Leifert JA, Baumann FT, Kleber M, lhorst G, et al. Exercise program improves therapy-related side-effects and quality of life in lymphoma patients undergoing therapy. Ann Oncol. 2014;25:493-9.

17. Kleckner IR, Kamen C, Gewandter JS, Mohile NA, Heckler CE, Culakova E, et al. Effects of exercise during chemotherapy on chemotherapy-induced peripheral neuropathy: a multicenter, randomized controlled trial. Support Care Cancer. 2018;26:1019-28.

18. Vollmers PL, Mundhenke C, Maass N, Bauerschlag D, Kratzenstein S, Röcken C, et al. Evaluation of the effects of sensorimotor exercise on physical and psychological parameters in breast cancer patients undergoing neurotoxic chemotherapy. J Cancer Res Clin Oncol. 2018;144:1785-92.

19. Bland KA, Kirkham AA, Bovard J, Shenkier T, Zucker D, Mckenzie DC, et al. Effect of exercise on taxane chemotherapy-induced peripheral neuropathy in women with breast cancer: a randomized controlled trial. Clin Breast Cancer. 2019;19:411-22.

20. Visovsky C, Bovaird JA, Tofthagen CS, Rice J. Heading off peripheral neuropathy with exercise: the hope study. Nurs Health. 2014;2:115-21.

21. Henke CC, Cabri J, Fricke L, Pankow W, Kandilakis G, Feyer PC, et al. Strength and endurance training in the treatment of lung cancer patients in stages IIIA/IIIB/IV. Support Care Cancer. 2014;22:95-101.

22. McCrary JM, Goldstein D, Boyle F, Cox K, Grimison P, Kiernan MC, et al. Optimal clinical assessment strategies for chemotherapy-induced peripheral neuropathy (CIPN): a systematic review and Delphi survey. Support Care Cancer. 2017;25:3485-93.

23. Cavaletti G, Jann S, Pace A, Plasmati R, Siciliano G, Briani C, et al. Multi-center assessment of the Total Neuropathy Score for chemotherapy-induced peripheral neurotoxicity. J Peripher Nerv Syst. 2006;11:135-41.

24. Vasquez S, Guidon M, Mchugh E, Lennon O, Grogan L, Breathnach OS. Chemotherapy induced peripheral neuropathy: the modified total neuropathy score in clinical practice. Ir J Med Sci. 2014;183:53-8.

25. Postma TJ, Aaronson NK, Heimans JJ, Muller MJ, Hildebrand JG, Delattre JY, et al. The development of an EORTC quality of life questionnaire to assess chemotherapy-induced peripheral neuropathy: the QLQ-CIPN15. Eur J Cancer. 2005;41:1135-9.

26. Smith EML, Knoerl R, Yang JJ, Kanzawa-Lee G, Lee D, Bridges CM. In search of a gold standard patient-reported outcome measure for use in chemotherapyinduced peripheral neuropathy clinical trials. Cancer Control. 2018;25:1073274818756608.

27. Lavoie Smith EM, Barton DL, Qin R, Steen PD, Aaronson NK, Loprinzi CL. Assessing patient-reported peripheral neuropathy: the reliability and validity of the European Organization for Research and Treatment of Cancer QLQ-CIPN15 Questionnaire. Qual Life Res. 2013;22:2787-99.

28. Müller J, Ringhof S, Vollmer M, Jäger LB, Stein T, Weiler M, et al. Out of balancepostural control in cancer patients before and after neurotoxic chemotherapy. Gait Posture. 2020;77:156-63.

29. Aaronson NK, Ahmedzai S, Bergman B, Bullinger M, Cull A, Duez NJ, et al. The European-Organization-for-Research-and-Treatment-of-Cancer Qlq-C30-a quality-of-life instrument for use in international clinical-trials in oncology. J Natl Cancer Inst. 1993:85:365-76.

30. Fayers P, Aaronson N, Bjordal K, Curran A, Groenvold M, Bottomley A. EORTC Scoring Manual - 3rd Edition. Brussels: European Organisation for Treatment of Cancer T4 - EORTC Quality of Life Study Group M4 - Citavi; 2001.

31. Yardley L, Beyer N, Hauer K, Kempen G, Piot-Ziegler C, Todd C. Development and initial validation of the Falls Efficacy Scale-International (FES-I). Age Ageing. 2005;34:614-9.

32. Lyman GH. Impact of chemotherapy dose intensity on cancer patient outcomes. J Natl Compr Canc Netw. 2009;7:99-108.

33. Nilsen TS, Scott JM, Michalski M, Capaci C, Thomas S, Herndon JE, et al. Novel methods for reporting of exercise dose and adherence: an exploratory analysis. Med Sci Sports Exerc. 2018;50:1134-41.

34. Campbell KL, Winters-Stone KM, Wiskemann J, May AM, Schwartz AL, Courneya $\mathrm{KS}$, et al. Exercise guidelines for cancer survivors: consensus statement from international multidisciplinary roundtable. Med Sci Sports Exerc. 2019;51:2375-90.

35. Hawley-Hague $H$, Horne M, Skelton DA, Todd C. Review of how we should define (and measure) adherence in studies examining older adults' participation in exercise classes. BMJ Open. 2016;6:e011560.

36. Zech A, Hubscher M, Vogt L, Banzer W, Hansel F, Pfeifer K. Balance training for neuromuscular control and performance enhancement: a systematic review. J Athl Train. 2010;45:392-403.

37. Taube W, Gruber M, Gollhofer A. Spinal and supraspinal adaptations associated with balance training and their functional relevance. Acta Physiol. 2008;193:101-16. 
38. Szuhany KL, Bugatti M, Otto MW. A meta-analytic review of the effects of exercise on brain-derived neurotrophic factor. J. Psychiatr Res. 2015;60:56-64.

39. Meneses-Echavez JF, Correa-Bautista JE, Gonzalez-Jimenez E, Schmidt Rio-Valle J, Elkins MR, Lobelo $F$, et al. The effect of exercise training on mediators of inflammation in breast cancer survivors: a systematic review with meta-analysis. Cancer Epidemiol. Biomark Prev 2016;25:1009-17.

40. Bland KA, Zadravec K, Landry T, Weller S, Meyers L, Campbell KL. Impact of exercise on chemotherapy completion rate: a systematic review of the evidence and recommendations for future exercise oncology research. Crit Rev Oncol Hematol. 2019;136:79-85.

41. Monfort SM, Pan X, Patrick R, Singaravelu J, Loprinzi $C L$, Lustberg $M B$, et al. Natural history of postural instability in breast cancer patients treated with taxane-based chemotherapy: a pilot study. Gait Posture. 2016:48:237-42.

42. Monfort SM, Pan X, Patrick R, Ramaswamy B, Wesolowski R, Naughton MJ, et al. Gait, balance, and patient-reported outcomes during taxane-based chemotherapy in early-stage breast cancer patients. Breast Cancer Res Treat. 2017;164:69-77.

43. Lacroix A, Hortobagyi T, Beurskens R, Granacher U. Effects of supervised vs. unsupervised training programs on balance and muscle strength in older adults: a systematic review and meta-analysis. Sports Med. 2017;47:2341-61.

44. Christensen JF, Jones LW, Andersen JL, Daugaard G, Rorth M, Hojman P. Muscle dysfunction in cancer patients. Ann Oncol. 2014;25:947-58.

45. Winters-Stone KM, Horak F, Jacobs PG, Trubowitz P, Dieckmann NF, Stoyles $S$, et al. Falls, functioning, and disability among women with persistent symptoms of chemotherapy-induced peripheral neuropathy. J Clin Oncol. 2017;35:2604-12.

46. Delbaere K, Close JC, Mikolaizak AS, Sachdev PS, Brodaty H, Lord SR. The Falls Efficacy Scale International (FES-I). A comprehensive longitudinal validation study. Age Ageing. 2010;39:210-6.

47. Maringwa J, Quinten $C$, King $M$, Ringash J, Osoba D, Coens $C$, et al. Minimal clinically meaningful differences for the EORTC QLQ-C30 and EORTC QLQ-BN20 scales in brain cancer patients. Ann Oncol. 2011;22:2107-12.

48. Seretny M, Currie GL, Sena ES, Ramnarine S, Grant R, Macleod MR, et al. Incidence, prevalence, and predictors of chemotherapy-induced peripheral neuropathy: a systematic review and meta-analysis. Pain. 2014;155:2461-70.

49. Park SB, Alberti P, Kolb NA, Gewandter JS, Schenone A, Argyriou AA. Overview and critical revision of clinical assessment tools in chemotherapy-induced peripheral neurotoxicity. J Peripher Nerv Syst. 2019;24:S13-25.

50. Bluethmann SM, Bartholomew LK, Murphy CC, Vernon SW. Use of theory in behavior change interventions. Health Educ Behav 2017;44:245-53.

\section{ACKNOWLEDGEMENTS}

We would like to thank all patients for participating in this study. We gratefully acknowledge Christine Boos, Charlotte Kreutz, and Laura Jansen for study implementation and conduction; all other members of the working group Exercise Oncology for further study assistance; Georges Sam (Department of Neurology, Heidelberg University Hospital) for excellent technical assistance in electrodiagnostics; the OnkoAktiv Network for training implementation; Frederik Marmé and Stefan Welte for medical support and help with recruitment; the NCT Cancer Registry and NCT Trial Center for data management support; Richard Schlenk and Martina Schmidt for statistical support.

\section{AUTHOR CONTRIBUTIONS}

According to CRediT taxonomy: conceptualisation (MW, AS, KS, WW and JW); data curation (JM, MW and JW); formal analysis (JM); funding acquisition (JW); investigation (JM, MW and JW); methodology (n/a); project administration (JM and JW); resources (MW, AS, GMH, KS and WW); software (n/a); supervision (JW); validation (MW, KS and JW); visualisation (JM); writing - original draft (JM); writing - review \& editing (all authors). All authors approved the final manuscript.

\section{FUNDING}

This project was supported by an intramural funding programme: Proof of concept trials 3.0, National Center for Tumor Diseases, Heidelberg, Germany (G876). Open Access funding enabled and organized by Projekt DEAL.

\section{ETHICS APPROVAL AND CONSENT TO PARTICIPATE}

Ethical approval for the PIC study was obtained (Ethics Committee Medical Faculty University of Heidelberg: S-630/2015, February 2, 2016). Written informed consent was obtained from all patients in accordance with The Code of Ethics of the World Medical Association (Declaration of Helsinki, 2013).

\section{CONSENT TO PUBLISH}

Not applicable.

\section{COMPETING INTERESTS}

The authors declare no competing interests.

\section{ADDITIONAL INFORMATION}

Supplementary information The online version contains supplementary material available at https://doi.org/10.1038/s41416-021-01471-1.

Correspondence and requests for materials should be addressed to J.W.

Reprints and permission information is available at http://www.nature.com/ reprints

Publisher's note Springer Nature remains neutral with regard to jurisdictional claims in published maps and institutional affiliations.

\begin{abstract}
c) (i)
Open Access This article is licensed under a Creative Commons Attribution 4.0 International License, which permits use, sharing, adaptation, distribution and reproduction in any medium or format, as long as you give appropriate credit to the original author(s) and the source, provide a link to the Creative Commons license, and indicate if changes were made. The images or other third party material in this article are included in the article's Creative Commons license, unless indicated otherwise in a credit line to the material. If material is not included in the article's Creative Commons license and your intended use is not permitted by statutory regulation or exceeds the permitted use, you will need to obtain permission directly from the copyright holder. To view a copy of this license, visit http://creativecommons. org/licenses/by/4.0/.
\end{abstract}

(c) The Author(s) 2021 